\title{
ANALISIS KELAYAKAN USAHA PADA BRAND ASRI KELURAHAN PADANG SERAI KECAMATAN KAMPUNG MELAYU KOTA BENGKULU
}

\section{ANALYSIS FEASIBILITY OF "BRAND ASRI" IN PADANG SERAI VILLAGE KAMPUNG MELAYU BENGKULU CITY}

\section{Rika Dwi Yulihartika, Fransius Siregar}

\author{
Program Studi Agribisnis, Fakultas Pertanian, UNIVED \\ Email : rikadwiyh13@gmail.com
}

\begin{abstract}
ABSTRAK
Metode penelitian yang dilakukan meliputi NPV, PBP (Payback periode) Pengumpulan data diambil dari data sekunder dan data primer, analisis data menggunakan rumus $\pi=\mathrm{TR}-\mathrm{TC}$ (Pendapatan Bersih), R/C Ratio untuk mengukur kelayakan usaha sirup BRAND ASRI.

Hasil penelitian menunjukkan bahwa dari segi aspek teknis dan operasional BRAND ASRI yang dekat dengan pasar yang berada di Kelurahan Padang Serai bahwa dari segi aspek teknis dan operasional layak untuk diusahakan, dari aspek pasar dan pemasaran BRAND ASRI mempunyai agen diberbagi kota salah satunya Padang, Pekanbaru dari segi pemasaran BRAND ASRI layak untuk pemasaran, dari aspek sosial dan ekonomi BRAND ASRI bagi masyarakat Kelurahan Padang Serai Mendukung adanya usaha ini sehingga kelompok tani bisa untuk menjual jeruk kalamansi kepada usaha BRAND ASRI dilihat dari sisi perekonomian BRAND ASRI sangat Layak, dari segi manajemen dan aspek hukum BRAND ASRI mempunyai struktur yang jelas, dan dari segi aspek hukum BRAND ASRI sudah layak karena usaha ini sudah diakui pihak IRT, MUI, dan diakui Halal untuk analisis finansial dan $\mathrm{R} / \mathrm{C}$ ratio, payback period BRAND ASRI dikatakan layak karena usaha ini lebih besar dari nol yaitu Rp 106.186.275,- dan analisis payback period diperoleh adalah 1.5 tahun untuk analisis R/C ratio BRAND ASRI secara ekonomis layak untuk diusahakan karena memiliki nilai lebih dari 1 sebesar $(\mathrm{R} / \mathrm{C} \geq 1.22)$.
\end{abstract}

Kata Kunci : Studi kelayakan, Keuangan, Sirup Kalamansi

\section{ABSTRACT}

Research methodology includes NPV, PBP (payback period) The collection of data taken from data secondary and data primary, analysis data using the formula $\pi=T R-T C$ (Net Revenue), R/C Ratio to measure the feasibility of syrup BRAND ASRI.

Terms of technical aspects and operational BRAND ASRI close to markets that are in the village of Padang Serai that in terms of technical aspects and operational feasible, of the market and marketing aspects BRAND ASRI has and agent various city one of Padang, Pekanbaru in terms of marketing BRAND ASRI eligible to marketing, from the social and economic aspects BRAND ASRI for the community village of Padang Serai Supporting their efforts so that the farmer groups could be to sell Calamansi to attempt BRAND ASRI in terms of the economy BRAND ASRI very worth it, in terms of management and legal aspects BRAND ASRI has a structure clear, and in terms of legal aspects BRAND ASRI is feasible 
because this business has recognized the IRT, MUI, and recognized Halal for financial analysis and R/C ratio, payback period BRAND ASRI is feasible because this business is greater than zero, namely $R p 106$ 186. 275, - and the analysis of the payback period is 1.5 years was obtained for analysis of $R / C$ ratio BRAND ASRI is economically feasible to be developed because it has more value than one of $(R / C \geq 1.22)$

Keywords : The feasibility study, Financial, Calamansi Syrup

\section{PENDAHULUAN}

Pembangunan

pertanian

dihadapkan kepada kondisi lingkungan yang strategis yang terus berkembang secara dinamis dan menjurus kepada liberalisasi perdagangan internasional, untuk memanfaatkan peluang yang ada, maka pembangunan pertanian harus lebih difokuskan kepada komoditi-komoditi unggulan yang dapat bersaing di pasar domestik maupun pasar internasional. Kondisi ini menjadi dasar yang kuat bagi pemerintah untuk mempercepat laju pembangunan pertanian di indonesia secara lebih modern dengan tujuan untuk memantapkan swasembada pangan sebagai dasar utama untuk menjaga stabilitas nasional (Daniel, 2002).

Salah satu kota yang terkenal akan buah buahannya dan budidaya sirup kalamansi nya adalah kota Bengkulu. Saat ini, kota Bengkulu terkenal sebagai penghasil sirup kalamansi, pada umum nya jeruk kalamansi (Citrofortunella microcarpa) atau disebut calamondin ini tidak secara langsung untuk dikonsumsi Hal ini juga menjadi masalah bagi para petani jeruk kalamansi, karena penjualan hasil panen mereka sangat terbatas.
Bertolak dari pada potensi dan keunikan dari jeruk kalamansi itu sendiri serta melihat keadaan saat ini, maka perlu dilakukan suatu usaha untuk memaksimalkan pemanfaatan hasil panen jeruk kalamansi. Salah satu usaha tersebut yaitu dengan mengolah jeruk kalamansi menjadi sirup jeruk kalamansi agar dapat dikonsumsi langsung oleh masyarakat (Anonim, 2010).

Oleh karena itu penulis tertarik untuk meneliti lebih lanjut dalam menganalisis kelayakan usaha pembuatan sirup kalamansi (Citrofortunella microcarpa) BRAND ASRI di Kelurahan Padang Serai Kecamatan Kampug Melayu Kota Bengkulu tersebut, karena BRAND ASRI merupakan usaha yang baru dalam memproduksi sirup kalamansi di Kota Bengkulu.

\section{METODOLOGI PENELITIAN}

Penelitian ini di lakukan pada usaha sirup BRAND ASRI Kelurahan Padang Serai Kecamatan Kampung Melayu Kota Bengkulu yang dilaksanakan pada bulan September - Oktober 2018.

Dalam penelitian ini, jenis penelitian yang digunakan adalah studi 
kasus dengan metode deskriptif pada perusahaan, yaitu dengan cara menganalisis data-data laporan keuangan yang kemudian ditabulasikan untuk menganalisis kelayakan usaha tersebut. Penelitian ini menggunakan pendekatan kuantitatif karena menggunakan data yang dapat diukur.

Data penelitian ini terdiri dari data primer dan sekunder. Data primer diperoleh dari hasil wawancara langsung dengan pihak pengelola/pihak yang terkait yang telah memproduksikan sirup kalamansi dalam proses tahap awal di BRAND ASRI di Kelurahan Padang Serai Kecamatan Kampung Melayu Kota Bengkulu. Data sekunder diperoleh melalui instansi yang terkait seperti, koordinator penyuluh usaha sirup

$$
\mathrm{NPV}=\sum_{t=0}^{n} \frac{B t-C t}{(1+i)^{t}}
$$

Dimana :

Bt = Penerimaan (benefit) bruto tahun ke-t

Dalam metode NPV, terdapat tiga penilaian kriteria investasi. Jika NPV suatu usaha `lebih besar dari nol (NPV $>0)$ berarti usaha tersebut layak dilakukan atau dilanjutkan karena memiliki arti, bahwa manfaat yang diperoleh lebih besar dari biaya yang dikeluarkan. Sebaliknya, jika kalamansi, website yang terkait, jurnal, dan buku.

\section{Metode Analisis Data}

Dalam melakukan analisis aspek finansial diperlukan kriteria investasi yang menyatakan usaha layak atau tidak untuk dijalankan. Kriteria investasi yang digunakan tersebut adalah:

1. Net Present Value (NPV)

Net Present Value (NPV) adalah suatu alat analisis untuk menguji kelayakan dari suatu investasi. NPV adalah nilai sekarang dari arus pendapatan yang ditimbulkan oleh investasi pada tingkat bunga tertentu atau dapat dikatakan sebagai selisih antara nilai bersih dari manfaat dan biaya pada setiap tahun kegiatan usaha.

$\mathrm{Ct}=$ Biaya $(\cos t)$ bruto tahun ke- $\mathrm{t}$

$\mathrm{N}=$ Umur Ekonomis Usaha

$\mathrm{t} \quad=$ Tahun

$\mathrm{i}=$ Tingkat suku bunga/discount rate

NPV usaha kurang dari nol $(\mathrm{NPV}<0)$, maka usaha tersebut tidak layak dilakukan atau dilanjutkan karena biaya yang dikeluarkan lebih besar dari manfaat yang diperoleh. Sedangkan, jika NPV sama dengan nol $(\mathrm{NPV}=0)$ manfaat yang diperoleh hanya cukup untuk menutup 
biaya yang dikeluarkan, artinya proyek mengembalikan persis sebesar modal sosial. Dengan demikian, usaha tersebut tidak untung dan tidak rugi.

2. Payback Periode (PBP)

Payback Periode atau analisis waktu adalah jumlah tahun yang dibutuhkan untuk menutupi pengeluaran awal. Kriteria ini mengukur kecepatan proyek dalam mengembalikan biaya awal. Oleh sebab itu, kriteria ini menghitung arus kas yang dihasilkan dan bukan besarnya keuangan akuntansi (Keown, 2001). Semakin kecil angka yang dihasilkan, maka usaha tersebut semakin baik untuk diusahakan. Perhitungan PBP menurut Kadariah et al. (1999) adalah sebagai berikut:

$$
\text { Payback Periode }=\frac{I}{A b}
$$

Dimana:

I = Besarnya investasi yang dibutuhkan

$\mathrm{Ab}=$ Benefit bersih yang dapat diperoleh setiap tahunnya

Pada dasarnya semakin cepat Payback Periode menandakan semakin kecil risiko yang dihadapi oleh investor. Untuk Mengetahui tingkat produksi dan produktivitas usaha sirup kalamansi di BRAND ASRI di Kelurahan Padang Serai Kecamatan Kampung Melayu Kota Bengkulu yang telah memproduksi sirup kalamansi ke berbagai kota dilakukan analisis secara tabulasi sederhana dengan fungsi sebagai berikut :

$$
\boldsymbol{\pi}=\mathbf{T R}-\mathbf{T C}
$$

Dimana :

$\pi$ (Pendapatan) $\quad=$ Pendapatan bersih (Rp/Ut)

TR(TotalRevenue) =Total Penerimaan (RP/Ut)

$\mathrm{TC}($ Total Cost $) \quad=$ Total Biaya (Rp/Ut)

Untuk Mengetahui layak atau tidak layak nya usaha sirup kalamansi BRAND ASRI di Kelurahan Padang Serai Kecamatan Kampung Melayu Kota Bengkulu adalah dengan menggunakan analisis Return Cost Ratio (R/C Ratio).

Biaya Produksi dihitung dengan rumus sebagai berikut :

$\mathrm{C}=\mathrm{FC}+\mathrm{VC}$

Dimana :

$\mathrm{C}($ Cost $)=$ Biaya Total $(\mathrm{RP})$

VC $($ Variabel Cost $)=$ Biaya Variabel (RP/Ut)

FC $($ Fixed Cost $) \quad=$ Biaya Tetap (Rp/Ut) 
Penerimaan adalah produksi dikali harga jual dengan rumus sebagai berikut :

$$
\mathbf{R}=\mathbf{P y} \mathbf{.} \mathbf{Y}
$$

Dimana :

$\mathrm{R}$ (Revenue) $=$ Penerimaan

Py $($ Price $) \quad=$ Harga Jual

$\mathrm{Y}($ Product $) \quad=$ Produksi $(\mathrm{Kg} / \mathrm{Ut})$

\section{HASIL DAN PEMBAHASAN}

\section{Aspek Pasar dan Pemasaran}

Pada penelitian ini, aspek pasar yang diteliti meliputi, prospek dan potensi pasar, daur hidup produk, dan bauran pemasaran BRAND ASRI. Produk sirup kalamansi yang dihasilkan BRAND ASRI memiliki pasar yang potensial dari peluang-peluang tersebut di atas. Pasar potensial tersebut menjadi peluang besar jika dilakukan program pemasaran yang efektif.

\section{Bauran Pemasaran}

Menurut Umar (2005), terdapat berbagai kegiatan yang harus dilalui oleh barang dan jasa sebelum sampai ke konsumen. Ruang lingkup kegiatan yang luas itu disederhanakan menjadi empat kebijaksanaan pemasaran yang dapat dikontrol yang biasa disebut bauran pemasaran. Bauran pemasaran adalah gabungan keempat strategi yang ada di dalamnya. Bauran pemasaran merupakan alat yang dipergunakan oleh pengusaha untuk mempengaruhi konsumennya yang
Dengan Kriteria sebagai berikut :

\section{$\mathbf{R} / \mathbf{C}$}

Jika $\mathrm{R} / \mathrm{C} \geq 1$, maka usaha sirup kalamansi secara ekonomis sangat layak diusahakan

Jika $\mathrm{R} / \mathrm{C}<1$, maka usaha sirup kalamansi secara ekonomis tidak layak diusahakan

tertarik, senang, kemudian membeli dan akhirnya puas akan produk tersebut. Karena itu, penetapan strategi bauran pemasaran memegang peranan penting dalam strategi pemasaran. Peranan ini dijalankan oleh perusahaan dengan mengkombinasikan bauran pemasaran yang paling sesuai dengan kondisi perusahaan, sehingga menghasilkan kondisi yang optimal.

1. Strategi Produk

Produk merupakan sesuatu yang dapat memenuhi kebutuhan dan keinginan konsumen. Strategi produk penting karena produk merupakan sesuatu yang dijual dan konsumen akan mengenal perusahaan melalui produk yang dijualnya

Produk yang dihasilkan BRAND ASRI termasuk barang yang dikonsumsi. Produk yang dihasilkan BRAND ASRI sirup kalamansi dengan berbagi macam kemasan botol, adapun strategi 
produk yang dihasilkan BRAND ASRI dengan menciptakan produk minuman yang memiliki nilai gizi yang tinggi, serta menciptakan merek kemasan, label yang telah dihasilkan. Komposisi semua sirup yang dihasilkan BRAND ASRI terdiri dari, 40 persen sari buah, 60 persen larutan gula pasir, Sedangkan komposisi dari semua jenis sirup yang dihasilkan BRAND ASRI terdiri dari, 70 persen sari buah, 30 persen larutan gula pasir, sirup buah yang diproduksi BRAND ASRI memiliki karakteristik, antara lain berbentuk cairan, beraroma, rasa khas buah, dan berwarna kuning untuk sirup, sirup jambu biji merah.

Semua produk sirup kalamansi dihasilkan dan dikemas dalam botol plastik dengan ukuran $1000 \mathrm{ml}, 500 \mathrm{ml}, 250 \mathrm{ml}$ melihat kencenderungan konsumen dihypermart sebagian konsumen membeli dengan kemasan yang berukuran $250 \mathrm{ml}$ karena harga tersebut tidak terlalu mahal BRAND ASRI juga melekatkan label pada setiap kemasan sirup buah. Di dalam label tersebut, BRAND ASRI mencantumkan merek dagang, nama produsen, manfaat minuman produk dan gizi, tanggal kadaluarsa, sertifikasi halal dengan. MUI, PIRT NO 2131771010631-18, dan barcode harga. Produk yang dihasilkan SEGAR ASRI layak untuk memasuki supermarket karena telah memiliki barcode harga. Penjelasan dalam label ini diinformasikan dalam tiga bahasa yakni, Indonesia, htal ini tentunya memudahkan konsumen saat ini BRAND ASRI telah mendistribusi produk keberbagai macam usaha seperti Hypermart, Supermarket, pasar hal ini dapat juga membantu produsen agar memiliki pemasukan yang cukup besar.

2. Strategi Harga

BRAND

ASRI

menggunakan harga dengan berbagai macam kemasan seperti pada tabel 1 .

3. Distribusi Pemasaran

Distribusi pemasaran adalah cara perusahaan menyalurkan barangnya, mulai dari perusahaan sampai ke tangan konsumen. Strategi distribusi penting dalam upaya perusahaan melayani konsumen tepat waktu dan tepat sasaran. 
Tabel 1. Daftar Harga Sirup Kalamansi BRAND ASRi

\begin{tabular}{|l|c|}
\hline \multicolumn{1}{|c|}{ Ukuran } & Harga \\
\hline $1000 \mathrm{ml}$ ( 1 Liter) & Rp 40.000,- \\
\hline $500 \mathrm{ml}(1 / 2$ Liter $)$ & Rp 22.500,- \\
\hline $250 \mathrm{ml}(1 / 4$ Liter $)$ & Rp 12.500,- \\
\hline
\end{tabular}

Produk-produk yang dihasilkan BRAND ASRI didistribusikan secara langsung tanpa melalui perantaraan distributor. BRAND ASRI menaruh produknya di beberapa outlet di Hypermart, BRAND ASRI mensuplai produknya ke beberapa tempat seperti, kantin atau koperasi sekolah dan kampus, gedung olahraga, kantor, minimarket Aneka Buana, dan tempat Hotel Splash yang berada disimpang 5 Kota bengkulu. BRAND ASRI juga memiliki agen di beberapa kota di Indonesia seperti, Pekanbaru, Padang, Medan.

4. Strategi Promosi

Strategi promosi merupakan salah satu cara untuk menarik perhatian dan mempertahankan konsumen. Perusahaan dapat menginformasikan segala jenis produk yang ditawarkan dan berusaha menarik calon konsumen baru melalui promosi yang dilakukan. Promosi yang dilakukan adalah dengan mengikuti pameran-pameran dan memberikan sampel gratis kepada pihak yang ingin memesan produknya. Promosi yang dilakukan BRAND ASRI masih menyebarkan nya dari mulut ke mulut, bekerjasama dengan pihak TELKOM Bengkulu, Stasiun RB Tv Bengkulu saat ini mereka cukup banyak konsumen untuk memesan produk tersebut.

\section{Hasil Analisis Aspek Manajemen}

BRAND ASRI sudah memiliki struktur organisasi yang jelas dan sudah adanya tugas dan wewenang untuk masing-masing tenaga kerja. Namun, tugas pemimpin usaha dalam mencari link pemasaran seharusnya dilakukan oleh bagian pemasaran. Hal ini bisa terjadi dikarenakan SDM dari bagian pemasaran yang kurang mampu untuk mencari link pemasaran, sehingga tugas ini diambil alih oleh pemimpin usaha. Karena itu, bagian pemasaran hanya bertugas untuk mengantarkan barang dan melakukan penjualan. Sedangkan untuk tenaga kerja yang lain sudah melakukan pekerjaannya sesuai dengan tugas dan wewenang 
masing-masing. Ini terlihat juga dari kesungguhan mereka melakukan tugas yang diberikan dan kehadiran tepat waktu sesuai jam kerja yang telah ditentukan walaupun saat ini terdapat beberapa tenaga kerja yang memiliki kemampuan dan komitmen yang rendah.

\section{Hasil Analisis Aspek Hukum}

Berdasarkan penjabaran di atas, dapat dikatakan bahwa BRAND ASRI layak dilihat dari aspek hukum. Hal ini dikarenakan, walaupun sebagian keterangan seperti, Akta Pendirian, Surat Keterangan Domisili Usaha, Nomor Pokok Wajib Pajak (NPWP), Tanda Daftar Perusahaan, Surat Izin Usaha Perdagangan (SIUP) belum diakui, BRAND ASRI tetap menjalankan usahanya karena BRAND ASRI masih tergolong industri rumah tangga.

BRAND ASRI masih merupakan industri rumah tangga yang telah didirikan oleh beberapa orang, BRAND ASRI baru didirikan pada tahun 2012. Ada beberapa jenis perizinan yang perlu disiapkan sebelum usaha dijalankan untuk mendapat legalitas usaha salah satunya P-IRT NO. 2131771010631-18, berdasarkan peraturan Kepala Badan Pengawas Obat dan Makanan Republik Indonesia tentang Pedoman Pemberian Sertifikat Produksi Pangan Industri BRAND ASRI mendapatkan Sertifikat Penyuluhan
Keamanan Pangan NOMOR : 631/1771/13, BRAND ASRI juga mempunyai Sertifikat HALAL yang keabsahan nya telah diakui oleh MUI (Majelis Ulama Indonesia) setelah melakukan pengujian dan pembahasan, menetapkan bahwa produk pangan, obatobatan, atau kosmetika ini adalah Halal menurut syariat islam dengan No : 11120001470915

\section{Produktivitas Sirup Kalamansi} BRAND ASRI Kelurahan Padang Serai Produksi merupakan konsep dari pada pengolahan (manufaktur) karena pengolahan ini hanyalah sebagai bentuk khusus dari produksi. Dan produktivitas merupakan sebuah konsep yang menggambarkan hubungan antara hasil (jumlah barang dan jasa yang diproduksi) dengan sumber (jumlah tenaga kerja, modal, tanah, energi, dan sebagainya) produksi dan produktivitas yang dihasilkan BRAND ASRI di daerah penelitian dapat dilihat pada tabel 2 .

\section{Pendapatan Bersih BRAND ASRI}

Penerimaan bersih BRAND ASRI adalah jumlah pendapatan dikurangi biaya total selama proses produksi. Pendapatan bersih yang diterima dalam produksi selama 1 bulan di daerah penelitian dapat dilihat pada Tabel 3 
Tabel 2. Produksi dan Produktivitas Sirup Kalamansi BRAND ASRI

\begin{tabular}{|c|c|c|c|}
\hline Tahun & Jumlah botol/b & oulan & Jumlah/bulan \\
\hline 2014 & $\begin{array}{l}\text { a. } 1000 \mathrm{ml} \text { (1 Liter) } \\
\text { b. } 500 \mathrm{ml} \text { (1/2 Liter) } \\
\text { c. } 250 \mathrm{ml} \text { (1/4 Liter }\end{array}$ & $\begin{array}{ll}=20 & \text { Botol } \\
=100 & \text { Botol } \\
=10 & \text { Botol }\end{array}$ & 130 Botol \\
\hline 2015 & $\begin{array}{l}\text { a. } 1000 \mathrm{ml} \text { (1 Liter) } \\
\text { b. } 500 \mathrm{ml} \text { (1/2 Liter) } \\
\text { c. } 250 \mathrm{ml} \text { (1/4 Liter) }\end{array}$ & $\begin{array}{l}=22 \text { Botol } \\
=105 \text { Botol } \\
=15 \text { Botol }\end{array}$ & 142 Botol \\
\hline 2016 & $\begin{array}{l}\text { a. } 1000 \mathrm{ml} \text { (1 Liter) } \\
\text { b. } 500 \mathrm{ml} \text { (1/2 Liter) } \\
\text { c. } 250 \mathrm{ml} \text { (1/4 Liter) }\end{array}$ & $\begin{array}{ll}=25 & \text { Botol } \\
=110 & \text { Botol } \\
=15 & \text { Botol }\end{array}$ & 150 Botol \\
\hline 2017 & $\begin{array}{l}\text { a. } 1000 \mathrm{ml} \text { (1 Liter) } \\
\text { b. } 500 \mathrm{ml} \text { (1/2 Liter }) \\
\text { c. } 250 \mathrm{ml} \text { (1/4 Liter })\end{array}$ & $\begin{array}{ll}=40 & \text { Botol } \\
=160 & \text { Botol } \\
=20 & \text { Botol }\end{array}$ & 220 Botol \\
\hline
\end{tabular}

Data Primer Diolah, 2018

Tabel 3 Pendapatan Bersih Usaha BRAND ASRI Selama Proses Produksi dalam 1 Bulan

\begin{tabular}{c|l|l|l}
\hline Tahun & \multicolumn{1}{|c|}{ Penerimaan } & \multicolumn{1}{c}{ Biaya } & $\begin{array}{c}\text { Jumlah } \\
\text { Pendapatan }\end{array}$ \\
\hline 2014 & Rp 3.175.000 & Rp 3.700.000 & Rp 670.000,- \\
\hline 2015 & Rp 3.430.000 & Rp 2.560.000 & Rp 870.000,- \\
\hline 2016 & Rp 3.662.500 & Rp 2.350.000 & Rp 1.312.500,- \\
\hline Total & Rp 15.717.500,- & Rp 11.160.000,- & Rp 5.752.500,- \\
\hline Rata-rata & Rp 3.929.375,- & Rp 2.790.000,- & Rp 1.438.125,- \\
\hline Data & Rp 5.450.000 & & Rp 2.550.000 \\
\hline
\end{tabular}

Data primer diolah, 2018

Dari Tabel 3 dapat diketahui bahwa jumlah penerimaan rata-rata yang yang diterima oleh BRAND ASRI sebesar Rp 3.929.375,- dan jumlah pendapatan bersih rata-rata per botol nya dalam 1 bulan Rp 1.438.125,- dalam hal 
ini pendapatan bersih yang diterima oleh BRAND ASRI ini cukup optimal meskipun usaha ini masih tergolong home industri.

\section{Analisis R/C Usaha BRAND ASRI}

Usaha BRAND ASRI dapat dikatakan menguntungkan atau tidak dengan cara menghitung nilai R/C. Suatu usaha dikatakan layak jika nilai $\mathrm{R} / \mathrm{C} \geq 1$ dan usaha BRAND ASRI dikatakan tidak layak jika nilai $\mathrm{R} / \mathrm{C} \leq 1$. Nilai $\mathrm{R} / \mathrm{C}$ ratio yang dihasilkan dari perhitungan usaha BRAND ASRI dalam 1 bulan dapat dilihat pada tabel 4 .

Berdasarkan Tabel 4 diketahui bahwa nilai R/C usaha BRAND ASRI di daerah penelitian adalah 1.22 sehingga usaha BRAND ASRI di Kelurahan Padang Serai Kecamatan Kampung Melayu Kota Bengkulu secara ekonomis layak untuk diusahakan di Kelurahan tersebut.
Usaha yang dilakukan BRAND

ASRI secara ekonomis layak untuk diusahakan walaupun kegiatan panen jeruk kalamansi hanya 3 kali dalam 1 minggu seharusnya kegiatan yang lebih optimal jika melakukan pemanenan setiap hari agar pasokan jeruk diproduksi lebih banyak. Ditempat penelitian ini juga mungkin baru dilaksanakan pada tahun 2012 sehingga BRAND ASRI belum begitu luas dalam pemasarannya. Dimana penerimaan yang dihasilkan BRAND ASRI lebih besar dari biaya yang dikeluarkan sehingga $\mathrm{R} / \mathrm{C}$ yang diperoleh adalah lebih dari 1 yaitu 1,22, sehingga menurut Soekartiwi (2006) apabila nilai $\mathrm{R} / \mathrm{C} \geq 1$ maka secara ekonomis usaha BRAND ASRI layak diusahakan.

Tabel 4. Nilai R/C BRAND ASRI di Kelurahan Padang Serai

\begin{tabular}{c|c|c}
\hline Nama Brand & $\mathbf{R} / \mathbf{C}$ & Keterangan \\
\hline BRAND ASRI & 1.22 & Layak \\
\hline
\end{tabular}

Data primer diolah, 2018 
Tabel 5. Tabel Penjualan Tahun 2014-2017

\begin{tabular}{|c|c|c|}
\hline Tahun & Jumlah & Pendapatan \\
\hline 2014 & $677 \mathrm{Kg}$ & Rp 14.800.000,- \\
\hline 2015 & $689 \mathrm{Kg}$ & $\mathrm{Rp} \mathrm{20.080.000,-}$ \\
\hline 2016 & $957 \mathrm{Kg}$ & $\mathrm{Rp} \mathrm{15.200.000,-}$ \\
\hline 2017 & $861 \mathrm{Kg}$ & $\mathrm{Rp} \mathrm{18.800.000,-}$ \\
\hline Jumlah & $3202 \mathrm{Kg}$ & $\mathrm{Rp} \mathrm{68.880.000,-}$ \\
\hline
\end{tabular}

\section{Biaya Operasional}

Tabel 6 Biaya Operasional BRAND ASRI Tahun 2014-2017 (Rp/Tahun)

\begin{tabular}{|c|c|c|c|c|}
\hline Keterangan / Tahun & 2014 & 2015 & 2016 & 2017 \\
\hline Penjualan & Rp 14.800.000 & Rp 15.200.000 & Rp 21.260.000 & Rp 18.800.000 \\
\hline \multicolumn{5}{|l|}{ Biaya Tetap } \\
\hline B. Administrasi & Rp 400.000 & Rp 400.000 & Rp 400.000 & $\mathrm{Rp} 400.000$ \\
\hline Pinjaman Bank & Rp 500.000 & Rp 500.000 & & \\
\hline \multicolumn{5}{|l|}{ Biaya Variabel } \\
\hline Gula & $\operatorname{Rp} 4.800 .000$ & Rp 5.400.000 & Rp 6.000.000 & Rp 6.960.000 \\
\hline Bahan baku & Rp 4.320.000 & Rp 4.320.000 & Rp 4.320.000 & Rp 4.320.000 \\
\hline Botol & $\operatorname{Rp} 220.000$ & Rp 400.000 & Rp 500.000 & $\operatorname{Rp} 600.000$ \\
\hline Label & Rp 80.000 & Rp 160.000 & Rp 200.000 & $\operatorname{Rp} 240.000$ \\
\hline Minyak tanah & $\operatorname{Rp} 40.000$ & $\operatorname{Rp} 40.000$ & $\operatorname{Rp} 40.000$ & Rp 40.000 \\
\hline Transportasi & Rp 50.000 & $\operatorname{Rp} 50.000$ & Rp 50.000 & Rp 50.000 \\
\hline Jumlah & Rp 10.410.000 & $\operatorname{Rp} 11.270 .000$ & Rp 11.420.000 & Rp 12.520 .000 \\
\hline
\end{tabular}

\section{Penerimaan Usaha}

Penerimaan dihitung dari perkiraan jumlah produksi dikalikan dengan harga jual. tahun-tahun awal produk BRAND ASRI sehingga belum banyak konsumen yang mengenal produk tersebut.

Pada tahun 2015 jumlah jeruk kalamansi sebesar $689 \mathrm{Kg}$, jumlah pendapatan yang diterima BRAND ASRI 20.080.000,-/tahun dan pada tahun 2014- 
2015 jumlah keseluruhan jeruk kalamansi menghasilkan $975 \mathrm{Kg}$ jeruk kalamansi dan jumlah pendapatan yang diterima pihak BRAND ASRI sebesar 21.260.000,/tahun, pada tahun 2017 BRAND ASRI menghasilkan jeruk kalamansi sebesar $861 \mathrm{Kg}$ jeruk kalamansi dan menghasilkan pendapatan 18.800.000,-/tahun dari jumlah keseluruhan pada tahun 2014-2017 bahwa peningkatan yang dialami sangat signifikan.

\section{Analisis Finansial}

Analisis kelayakan finansial BRAND ASRI menggunakan prinsip nilai uang saat ini tidak sama dengan nilai uang dimasa akan datang. Analisis ini dilakukan dengan menggunakan kriteriakriteria penilaian investasi yaitu, Net Present Value (NPV), Payback pariode (PBP)

$\begin{array}{ccr}\text { Hasil } & \text { analisis } & \text { finansial } \\ \text { menunjukkan } & \text { bahwa NPV usaha }\end{array}$
pembuatan sirup kalamansi ini lebih besar dari nol yaitu, NPV menunjukkan nilai sebesar rata-rata $\mathrm{Rp}$ 106.186.275. hal ini menunjukkan usaha yang akan dijalankan BRAND ASRI memberikan manfaat bersih sebesar Rp 106.186.275,- dengan kapasitas produksi botol 3.263 botol selama kurun 4 tahun
Payback period yang diperoleh adalah 1.5 tahun atau sama dengan 1 tahun setengah. Hal ini berarti, usaha dapat mengembalikan modal sebelum umur usia berakhir. Nilai Payback period ini cukup singkat, sehingga usaha ini layak untuk dijalankan. Hasil perhitungan kriteria kelayakan tersebut dapat dilihat pada tabel 7.

\section{KESIMPULAN}

1. Hasil analisis aspek non finansial yaitu, aspek pasar, aspek teknis, aspek manajemen, aspek sosial dan lingkungan, serta aspek hukum menunjukkan bahwa usaha yang dijalankan BRAND ASRI ini layak untuk dilaksanakan. Namun, pada aspek pasar, kegiatan promosi yang dilakukan belum optimal karena BRAND ASRI hanya mengandalkan keikutsertaan dalam pameranpameran dan informasi dari mulut ke mulut. BRAND ASRI juga mengalami kendala pada aspek manajemen karena BRAND ASRI belum mempunyai karyawan tetap. 
Tabel 7. Hasil Perhitungan Kriteria Kelayakan Finansial BRAND ASRI Bengkulu

\begin{tabular}{|c|c|}
\hline Kriteria Kelayakan Finansial & Hasil \\
\hline NPV & Rp 106.186.275,- \\
\hline PBP & 1,5 Tahun \\
\hline R/C & 1.22 \\
\hline
\end{tabular}

2. Hasil analisis produksi dan ekonomis untuk diusahakan lebih produktivitas pada usaha BRAND ASRI di Kelurahan Padang Serai Kecamatan Kampung Melayu Kota Bengkulu dengan rata-rata 130 botol - 220 botol/ bulan. Dengan jumlah sebanyak ini BRAND ASRI telah memproduksikan sirup ini sampai ke luar kota sehingga produk ini akan semakin meningkat dan mengalami potensial yang sangat pesat.

3. Total pendapatan bersih yang diterima oleh BRAND ASRI dalam 1 bulan adalah sebesar $\mathrm{Rp}$ 1.438.125,- Dari pendapatan bersih yang dihasilkan oleh BRAND ASRI ini cukup signifikann karena usaha ini masih skala Industri rumah tangga, sehingga usaha ini belum banyak dikenal bagi konsumen khususnya masyarakat Kota Bengkulu.

4. Analisis $\mathrm{R} / \mathrm{C}$ ratio pada usaha BRAND ASRI menunjukkan angka 1.22 sehingga layak secara

\section{DAFTAR PUSTAKA}

Daniel, Mochar. 2002. Pengantar Ekonomi Pertanian. Bumi Aksara. Jakarta

Departemen Pertanian. 2011. Budidaya Jeruk Kalamansi. http://epetani.deptan.go.id/budiday a/budidaya-jeruk-kalamansi-citrusmicrocarpa-1621 3 Novemper 2011 diakses tanggal 3 mei 2018.

Gittinger. 1986. Analisa Ekonomi ProyekProyek Pertanian. UI-Press. Jakarta

Gleekapay, M. 2008. Manajemen Produktivitashttp://www/hrsdm.or g (diakses pada tanggal 11 September 2018).

Husnan S, Suwarsono. 2000. Studi Kelayakan Proyek. Unit Penerbit dan Pencetak AMP YKPN. Yogyakarta 
Kadariah, Karlien L, Clive G. 1999. Pengantar Evaluasi Proyek. Fakultas Ekonomi dan Manajemen Universitas Indonesia. Jakarta

Kadariah, Karlien L, Clive G. 1999. Pengantar Evaluasi Proyek. Fakultas Ekonomi dan Manajemen Universitas Indonesia. Jakarta

Karo-karo, Feryanto W. 2010. Pupuk dan Subsidi : Kebijakan yang Tidak Tepat Sasaran. http://feryanto.wk.staff.ipb.ac.id (diakses tanggal 11 September 2018)

Kasmir, Jakfar. 2006. Studi Kelayakan Bisnis. Kencana. Bogor:

Mahasin A. 2007. Analisis Brand Equity "Ekuitas Merek" Minuman Sirup dan Implikasinya dalam Kegiatan Pemasaran (Kasus Merek ABC di Giant Hypermarket Margo City Depok [skripsi]. Fakultas Teknologi Pertanian, Institut Pertanian Bogor. Bogor

Makeham. J.P. 1991. The Economics of Tropical Farm Management (terjemahan). LP3ES. Jakarta.

Maulana, M. 2004. Peranan luas lahan, Intensitas Pertanaman Dan Produktivitas Sebagai Sumber
Pertumbuhan Padi Sawah Di Indonesia 1980-2001. Jurnal Agro Ekonomi, Vol 22 No. 1, Mei 2004: 74-95. Pusat Pengembangan dan Penelitian Sosial Ekonomi Pertanian. Bogor.

Potter NH, Hotchkiss. 1995. Food Science. 5th Edition. Chapman and Hall Co. Inc. New York

Prawirokusumo, Soeherto. 2001. Ilmu Usaha Tani. BPFE. Yogyakarta

Sari, Reny Puspita. 2011. Analisis Nilai Tambah dan Kelayakan Usaha Agroindustri Chip Ubi Kayu Sebagai Bahan Baku Pembuatan MOCAF (Modified Cassava Flour) di Kabupaten Trenggalek. Malang.

Satuhu S. 2004. Penanganan dan Pengolahan Buah. Penebar Swadaya. Jakarta

Subagyo A. 2007. Studi Kelayakan: Teori dan Aplikasi. Gramedia. Jakarta

Umar H. 2005. Studi Kelayakan Bisnis. Ed ke-3. Gramedia. Jakarta

Wahyu Widyastuti., Bengkulu di Mata: Analisis Branding Sirup Jeruk Kalamansi Produksi Koperasi Kultura Kalamansi Bengkulu, tth, PT Unib Swara, Hal. 165-180 